\title{
O QUE REPRESENTA A ATENÇÃO PARA A EPISTEMOLOGIA DA APRENDIZAGEM NA CONTEMPORANEIDADE? - A PERCEPÇÃO DOCENTE
}

\author{
¿QUÉ REPRESENTA LA ATENCIÓN PARA LA EPISTEMOLOGÍA DEL \\ APRENDIZAJE EN LA CONTEMPORANEIDAD? - LA PERCEPCIÓN DOCENTE
}
WHAT DOES THE ATTENTION FOR THE EPISTEMOLOGY OF LEARNING IN CONTEMPORANEITY REPRESENT? - THE TEACHERS PERCEPTION

\author{
Arnaldo NOGARO ${ }^{1}$ \\ Hildegard Susana $\mathrm{JUNG}^{2}$ \\ Estela Mari Santos SIMÕES ${ }^{3}$
}

RESUMO: O artigo resulta de pesquisa ${ }^{4}$ de campo com o objetivo de identificar e interpretar fatores interferentes nos processos atencionais em estudantes dos anos iniciais do Ensino Fundamental e seu impacto na aprendizagem escolar no contexto contemporâneo, na percepção de seus professores. O estudo tem abordagem qualitativa, com coleta empírica e bibliográfica de dados, e o tratamento dos achados seguiu as orientações da Análise de Conteúdo. A atenção é fator fundamental para a aprendizagem, no entanto, o que se constata são comportamentos que levam ao questionamento sobre como as crianças do início da escolaridade agem em relação a ela em sala de aula. Os achados apontam para: a) com relação às causas da desatenção figuram problemas familiares, uso das tecnologias e a metodologia utilizada pelo professor; b) a atenção é considerada um pré-requisito no processo de aprender; c) os professores têm necessidade de chamar a atenção dos estudantes com grande frequência; d) o estudante atento é caracterizado participante e o desatento é mais apático; e) a representação dos professores sinaliza relação entre as tecnologias e a desatenção. Conclui-se que o professor precisa manter o olhar sensível e vigilante em sua prática e a forma como organiza e conduz a aula para reconstruir o planejamento e repensar suas estratégias sempre que necessário, no sentido de atender às características dos aprendizes que atende, em um movimento que colabore a uma melhor compreensão da epistemologia da aprendizagem.

PALAVRAS-CHAVE: Atenção. Motivação. Ensino fundamental. Percepção docente.

RESUMEN: El artículo resulta de investigación de campo con el objetivo de identificar e interpretar factores interferentes en los procesos atencionales en estudiantes de los años

\footnotetext{
${ }^{1}$ Universidade Regional Integrada do Alto Uruguai e das Missões (URI), Santo Ângelo - RS - Brasil. Professor doutor do Programa de Pós-Graduação em Educação e Pró-Reitor de Ensino. ORCID <http://orcid.org/0000-0003-0517-0511>.E-mail: narnaldo@uri.com.br

${ }^{2}$ Universidade La Salle (Unilasalle), Canoas - RS - Brasil. Professora do Curso de Pedagogia. Doutora em Educação. Integrante do Grupo de Pesquisa Gestão Educacional em Diferentes Contextos. ORCID <http://orcid.org/0000-0001-5871-3060>. E-mail: hildegard.jung@unilasalle.edu.br

${ }^{3}$ Universidade Regional Integrada do Alto Uruguai e das Missões (URI), Frederico Westphalen - RS Brasil. Professora Mestre em Educação da Rede pública estadual do RS. ORCID <http://orcid.org/00000002-7587-8286>. E-mail: estelasimoes89@gmail.com.

${ }^{4} \mathrm{O}$ projeto da pesquisa tramitou e foi aprovado em Comitê de ética sob o $\mathrm{n}^{\mathrm{o}} \mathrm{CAAE}-51529115.4 .0000 .5351$.
}

RIAEE - Revista Ibero-Americana de Estudos em Educação, Araraquara, v. esp, n. 3, p. 2026-2040, dez., 2018. E-ISSN: $1982-5587$. 
iniciales de la Enseñanza Fundamental y su impacto en el aprendizaje escolar en el contexto contemporáneo, en la percepción de sus profesores. El estudio tiene abordaje cualitativo, con colecta empírica y bibliográfica de datos, y el tratamiento de los hallazgos siguió las orientaciones del Análisis de Contenido. La atención es factor fundamental para el aprendizaje, pero lo que se constata son comportamientos que llevan al cuestionamiento sobre cómo actúan los niños del comienzo de la escolaridad con relación a ella en clase. Los hallazgos señalan: a) con relación a las causas de la desatención figuran problemas familiares, uso de las tecnologías y la metodología utilizada por el profesor; b) la atención es considerada un pre-requisito en el proceso de aprender; c) los profesores necesitan llamar la atención a los estudiantes con gran frecuencia; d) el estudiante atento es caracterizado como participante y el desatento es más apático; e) la representación de los profesores señala relación entre las tecnologías y la desatención. Se concluye que el profesor necesita mantener la mirada sensible y vigilante a su práctica y a la forma como organiza y conduce la clase para reconstruir el planeamiento y repensar sus estrategias siempre que necesario, en el sentido de atender a las características de los aprendices que atiende.

PALABRAS CLAVE: Atención. Motivación. Enseñanza fundamental. Percepción docente.

ABSTRACT: This article is the result of a field research with the objective of identifying and interpreting interfering factors in the attentional processes in students from the initial years of elementary school and its impact on school learning in the contemporary context, in the perception of its teachers. The study has a qualitative approach, with empirical and bibliographical data collection, and the treatment of the findings followed the guidelines of the Content Analysis. Attention is a fundamental factor for learning, however, what is observed are behaviors that lead to the questioning about how children at the beginning of schooling act in relation to it in the classroom. The findings result: a) regarding the causes of inattention, there are family problems, use of the technologies and the methodology used by the teacher; b) attention is considered a prerequisite in the learning process; $c$ ) teachers need to draw students' attention very often; $d$ ) the attentive student is characterized participant and the inattentive is more apathetic; e) the representation of teachers signals a relationship between technologies and inattention. It is concluded that the teacher needs to be attentive and vigilant in his practice and the way he organizes and leads the class to reconstruct the planning and rethink his strategies whenever necessary, in order to meet the characteristics of the apprentices he attends.

KEYWORDS: Attention. Motivation. Elementary school. Teacher perception.

\section{Introdução}

A evolução tecnológica e industrial contemporânea traduz-se numa dinâmica muito diferente de algumas décadas passadas. Criamos artefatos de comunicação, novos meios de transmissão de informação, estabelecemos novos horários de trabalho, empresas de comércio e serviços, indústrias ficam em operação em horários mais variados fazendo com que o "sistema nunca durma". Castells (2000) refere-se a esta condição como 
"esquizofrenia estrutural" entre a função e o significado, na qual os padrões de comunicação ficam sob tensão crescente. Como consequência temos o ativismo, a dinâmica do "progresso" e o barulho como resultado.

Ao voltarmos nosso olhar para a realidade educacional, especialmente para as salas de aula, constatamos a dificuldade dos professores para atrair a atenção dos estudantes, para se fazer ouvir. Acreditamos que abordar este tema e pesquisar sobre o mesmo como subsídio para a formação de professores numa perspectiva contemporânea torna-se fundamental para despertar a necessidade de reavaliar o que ocorre em sala de aula, especialmente no tocante à falta de atenção. Esse movimento caminha lado a lado com uma necessária compreensão da epistemologia da aprendizagem.

Trata-se de uma pesquisa de campo, exploratória, de natureza qualitativa, realizada com dezoito professores, três por escola, que atuam em seis estabelecimentos na rede pública e privada do norte do estado do Rio Grande do Sul. A pesquisa teve como objetivo identificar a representação dos professores sobre os fatores interferentes nos processos atencionais em estudantes dos anos iniciais do Ensino Fundamental e seu impacto na aprendizagem. A coleta de dados ocorreu por meio de questionários de questões abertas ${ }^{5}$, e revisão bibliográfica baseada em autores como Cosenza (2015), Izquierdo (2002), Brandão (2004), Fernández (2012), De-Nardin e Sordi (2008), Tacca (2008), dentre outros. A análise e interpretação dos achados foi realizada utilizando a Análise de Conteúdo baseada em Bardin (2008). Os sujeitos ${ }^{6}$, com entre cinco e 12 anos de experiência no magistério, foram escolhidos de forma aleatória por adesão.

A arquitetura do artigo apresenta, na sequência, a representação dos professores com relação à atenção e aprendizagem e o impacto da primeira sobre a segunda. $\mathrm{O}$ tópico seguinte dedica-se à percepção sobre atenção versus desatenção em sala de aula, bem como as características de alunos identificados como atentos e desatentos. Logo após, versamos sobre fatores que determinam a desatenção em sala de aula na opinião dos participantes da pesquisa. O último apartado trata da tecnologia enquanto motivo de desatenção. Fecham o artigo as considerações finais e referências que embasaram o estudo.

\footnotetext{
${ }^{5}$ Foram enviadas seis perguntas aos participantes por correio eletrônico, a saber: 1. Você percebe relação entre atenção e aprendizagem?; 2. Existe impacto da atenção na aprendizagem?; 3. Você precisa chamar a atenção dos seus estudantes? Com que frequência?; 4. Como você caracteriza o estudante atento em sala de aula? E o desatento?; 5. Na sua opinião, que fatores determinam a desatenção em sala de aula?; 6. Na sua opinião, há relação entre tecnologias e desatenção?

${ }^{6}$ Para preservar a identidade dos participantes da pesquisa, adotamos a letra $\mathrm{P}$ (de professor), seguida da numeração sequencial utilizada para a organização dos dados. Também adotamos o formato itálico para diferenciar as respostas dos sujeitos do referencial teórico e das inferências dos autores.
} 


\section{Relação entre atenção e aprendizagem}

A origem latina de atenção, attendere, significa "entrar em contato", ou seja, é uma conexão que se faz com o que está ao nosso redor. Podemos dizer também que “[...] a atenção tem muitos significados. Ela envolve estar desperta, consciente e atenta, isso sem mencionar as deficiências relacionadas a ela" (GAZZANIGA, 2006, p. 264). A atenção é resultado do funcionamento integrado de inúmeras estruturas corticais e sub-corticais, além de sistemas de redes neurais e "[...] está estreitamente vinculada à chamada memória de trabalho" (POZO, 2002, p. 146). Constitui-se em um mecanismo que opera basicamente de duas formas: transfere ou alerta para perigos, selecionando os estímulos mais relevantes do meio, bem como monitora as informações que chegam, para definir o foco naquilo que possa interessar.

A epistemologia da aprendizagem torna-se assunto que não pode ser ignorado na contemporaneidade, posto que, de acordo com Dutra (2000), é impossível separar saber que, de saber como. Segundo o autor, isto significa que a aprendizagem precisa estar atrelada à investigação. Este conceito, segundo ele, consiste na “[...] transformação controlada e dirigida de uma situação indeterminada (de dúvida) em uma outra de tal forma determinada de modo a converter os elementos da situação original em um todo unificado em suas distinções constitutivas e relações" (DUTRA, 2000, p. 171).

No que concerne aos sujeitos desta pesquisa, ao serem interrogados sobre a relação entre atenção e aprendizagem, 100\% dos professores responderam que identificam esta relação, coincidindo com o que encontramos em Cosenza (2015, p. 30): "A atenção é essencial para aprendizagem, pois só será registrado na memória o que tiver passado pelo filtro da atenção". Os argumentos para justificar esta relação são apresentados por P1 a partir de quem a atenção é um pré-requisito no processo de prender, graças a ela há memorização e adquire-se conhecimento.

Com relação ao impacto na aprendizagem, P3 afirma que crianças que se distraem facilmente demandam um tempo maior para aprender, requerem novas estratégias e abordagens. Este comportamento docente vem ao encontro do que Ffiel (2016) revela sobre os profissionais que acreditam que todas as crianças são aprendizes ativos e poderosos. Segundo o autor, estes docentes descobrem maneiras de aprimorar os interesses e a curiosidade das crianças.

P5 expõe que a aprendizagem se torna significativa quando associada a algum conhecimento prévio da criança. Quando ela cria pontes entre o novo e o já conhecido, é 
mais fácil assimilar. Teóricos confirmam que quando possuímos algum conhecimento prévio de um assunto nos envolvemos mais facilmente e isso desperta nosso interesse: "O cérebro está sempre disposto a prestar atenção, mas ele a direciona para estímulos significativos, ou seja que despertam interesse porque podem trazer consequências importantes para o indivíduo" (COSENZA, 2015, p. 27).

A resposta mais próxima do que a literatura traz sobre a relação entre atenção e aprendizagem foi manifestada por P10: Alunos atentos conseguem aprender com mais facilidade porque detém a atenção no que é importante, explicações dos conteúdos ou do que os mesmos apresentam dificuldade. Muitas pessoas pensam que a atenção tem a ver somente com o que está ao nosso redor ou no ambiente externo, imaginando que o fator preponderante que a compromete possa estar nos "ruídos" dos ambientes em que nos encontramos. Acreditam que basta "isolar-se" ou criar mecanismos que reduzem ou eliminam o barulho e tudo estará resolvido, mas estudos indicam que não é desta forma simples que funciona. "A cada instante o ser humano é bombardeado com inúmeras informações, quer externas provenientes do meio ambiente, quer internas provenientes do próprio organismo" (PINTO, 2001, p. 18).

A atenção conecta-se com a memória de trabalho que é nossa memória mais fugaz e dinâmica, por onde circulam muitos dados e informações que permanecem por um tempo muito curto. Mesmo que os dados permaneçam por pouco tempo, ou seja, uma espécie de "memória de passagem", para que cheguem à memória de curta ou longa duração, obrigatoriamente precisam passar por ela. A porta de entrada das informações para a memória de trabalho é a atenção. Ou prestamos atenção ou não haverá aquisição. Em outras palavras, para toda e qualquer aprendizagem se faz necessária à atenção. "O estudante tem de focar a atenção no que o professor diz e ao mesmo tempo tentar abstrairse das informações circundantes produzidas pelos colegas ou por ruídos fora da sala" (PINTO, 2001, p. 19).

Aqui surge outra questão importante: nossa memória de trabalho depende da atenção que prestamos aos eventos que ocorrem, mas ao mesmo tempo não temos um controle total sobre ela, pois interferem elementos ou recordações que podem "retornar" de nossas memórias (de curta e longa duração) e fazer-se presentes a qualquer momento, ser evocadas na memória de trabalho mesclar-se com as novas informações. Ora, isso demonstra a importância do que Golleman (2014, p. 53) denomina de "nossas vozes internas". Para ele, não é a conversa das pessoas ao nosso redor que tem mais poder de nos distrair, mas o que habita nossa própria mente. "A concentração absoluta exige que essas

RIAEE - Revista Ibero-Americana de Estudos em Educação, Araraquara, v. esp, n. 3, p. 2026-2040, dez., 2018. E-ISSN: $1982-5587$. 
vozes internas calem” (Id.). Quanto mais nossa mente divaga, menor será nossa capacidade de concentrar-se no que está ocorrendo e consequentemente de aprender e capturar o que nos interessa.

Quando recorremos à literatura que trata da formação de memórias, aquisição de conhecimento, uma das primeiras questões abordadas, é a questão do elemento determinante para que haja "entrada" ou aquisição de uma informação. Se ela vai permanecer por pouco ou muito tempo, é outra questão, mas só há uma maneira de se constituir uma memória de longa duração: passar pelo filtro da atenção. De acordo com Izquierdo (2002, p. 9), "Memória é a aquisição, a formação, a conservação e a evocação de informações. A aquisição é também chamada de aprendizagem: só "grava-se" aquilo que foi aprendido". O autor ainda se refere à evocação como uma recordação, uma lembrança recuperada. Segundo ele, somente recordamos o que ficou gravado, o que aprendemos.

Nesta perspectiva, a memória não é um sistema único, uma vez que envolve sistemas paralelos e independentes, sofre a interferência de outros fatores (atenção, motivação e ansiedade), e tem um papel fundamental na aquisição do conhecimento e aprendizagem.

\section{Atenção x desatenção em sala de aula}

Questionamos os professores a respeito da necessidade de chamar a atenção dos estudantes e com que frequência o fazem. Eles foram unânimes, dizendo que sim, que chamam a atenção. Alguns com maior, outros com menor frequência, e ainda há aqueles que responderam sempre. A primeira questão importante a ser observada é que esses professores trabalham com crianças de seis a doze anos, e todos sabemos o quanto são ativas. Temos a ilusão e a pretensão de que a criança, quando chega à escola, transforma-se em estudante, dedicando-se plenamente ao estudo e deixando todos os seus outros desejos, vontades de lado, sufocando-os em nome do aprender. Isto é um engano, daí a necessidade permanente de o professor não esquecer que, quando pede a uma criança pequena que preste atenção, "devemos reconhecer que qualquer falha em obedecer a esse pedido não pode resultar de tédio, teimosia ou distração, mas do fato de que ela não tem o conhecimento e a habilidade necessários para dedicar à tarefa ou ao tópico que lhe são apresentados" (WOOD, 2003, p. 97). 
Dessa maneira, os professores afirmam que chamar a atenção pode ser considerado "algo normal" dentro da sala de aula. Daí a função estratégica para quem estudou e profissionalizou-se para trabalhar com esse público: o professor. Segundo P1, os estudantes precisam de estímulos, precisam de incentivo e motivação para que mantenham o foco por mais tempo. $\mathrm{O}$ ambiente de uma criança está repleto de informações, novidades e estímulos. Talvez por isso seja difícil para ela manter a atenção, a concentração nos estudos e nas suas tarefas de um modo particular.

P2 destaca que todo dia se faz necessário algum tipo de combinado, alguma espécie de diálogo para retomar a atenção e dar continuidade à aula. P3 lembra que temos uma diversidade muito grande em sala de aula, crianças com diferentes características, algumas mais inquietas, outras menos. É com essa diversidade que o professor tem que trabalhar. Para Vickery (2016) é absolutamente crucial que sejam levados em conta os interesses e as diferenças individuais e que todos os indivíduos recebam a oportunidade de gerar suas próprias indagações. A ideia de homogeneidade e silêncio absoluto são fictícias.

Ao longo da história da trajetória da escola, vamos encontrar muitas tentativas para "acomodar" as crianças, algumas de teor altamente repressor, tendo-se recorrido até à violência, em muitos casos, como foi o período em que eram utilizados castigos físicos e a palmatória para que os estudantes voltassem seus interesses para o estudo. Esses recursos foram abolidos e hoje trabalhamos com outras estratégias, embora algumas ainda discutíveis, como ameaças, bullying, "o cantinho da vergonha", a retirada do recreio, etc.

P13 nos faz pensar, quando afirma que nem crianças, nem adultos conseguem manter a atenção focada todo o tempo, e que a atenção vai depender do momento e dos estímulos. Ressalta que a atenção também depende de como a criança está emocionalmente ou fisicamente naquele dia. Kastrup (2004) faz distinção entre a dispersão e a distração. A dispersão consiste num repetido deslocamento do foco atencional, que impossibilita a concentração, a duração e a consistência da experiência. A distração é um funcionamento no qual a atenção experimenta a errância, fugindo do foco da tarefa para a qual é solicitada a atenção, indo na direção de um campo mais amplo, habitado por pensamentos fora de lugar, percepções sem finalidade, reminiscências vagas, objetos desfocados e ideias fluidas, que advêm do mundo interior ou exterior, mas que têm em comum o fato de serem refratárias ao apelo da tarefa em questão. Por outro lado, o distraído pode ser alguém “extremamente concentrado, que não é meramente desatento, mas cuja atenção se encontra em outro lugar" (KASTRUP, 2004, p. 8).

RIAEE - Revista Ibero-Americana de Estudos em Educação, Araraquara, v. esp, n. 3, p. 2026-2040, dez., 2018. E-ISSN: 1982-5587. 
A mesma autora faz referência a uma atenção que denomina de inventiva ou criadora, isto é, que se diferenciaria da atenção rotineira vinculada à realização de tarefas ou solução de problemas. Ela exige um aprendizado, um esforço superior para que ocorra: "Aprende-se fazendo, ou melhor, aprende-se no trabalho atento (learning on the job), e não através do exercício mecânico. É a atenção que é treinada" (KASTRUP, 2004, p. 12). Assim, questiona se a atenção seria condição ou efeito da aprendizagem. Instaura um ponto de vista sob o qual pensar a atenção envolve, em primeiro lugar, uma ampliação do conceito de atenção em relação ao ato de prestar atenção a tarefas e de buscar informações. Em segundo lugar, modifica-se o modo de colocar o problema da relação entre atenção e aprendizagem. O problema de atenção que é requerida para que um processo de aprendizagem tenha lugar é substituído pelo problema da própria aprendizagem da atenção.

Às vezes, esquecemos que quando vamos à escola, nosso corpo vai junto. Embora haja um trabalho importante para nosso cérebro e nossa mente, eles dependem do que ocorre com o corpo para manter-se estáveis. O cérebro é a parte física que dá suporte à mente e ela depende diretamente das condições orgânicas do pensar. Com nossas emoções não é diferente. Elas são o resultado de mudanças que ocorrem com nosso corpo e nossa mente. Refletem nossa condição naquele dado momento, portanto, se algo nos desestabilizou, ou nossa mente possui uma preocupação que a forma, teremos dificuldades para prestar atenção ao que a professora nos propõe. Sob o olhar de Wood (2003, p. 9091), "sentar, prestar atenção, escutar atentamente ou observar diligentemente o desempenho de um adulto, em relação a uma tarefa estabelecida por esse adulto, levam a exigências de concentração, memória e pensamento que não são um aspecto da aprendizagem incidental."

P17 afirma que estudantes que demoram e dispersam a atenção são desorganizados com o seu material. Como são desatentos, não prestam atenção a certos detalhes $e$ processos que demandam organização e daí se dispersam quando precisam realizar uma tarefa, pois não sabem exatamente do que vão precisar para realizá-la. Neste sentido, Wood (2003, p. 271) alerta dizendo que quando precisamos muito frequentemente repetir "Prestem atenção! [...] em sala de aula, isso provavelmente é um sinal de que a distância entre o que as crianças compreendem e aquilo que lhes é exigido é grande demais para elas cobrirem." Resta-nos vigiar atentamente a prática pedagógica desempenhada neste sentido. 


\section{Características de estudantes atentos e desatentos em sala de aula}

Os professores foram interrogados a respeito de como caracterizam o estudante atento e também o desatento em sala de aula. Neste sentido, mencionam que há certa dificuldade para caracterizar um estudante como atento, pois cada um possui uma singularidade específica, mas há algumas características que podem ser identificadas como: participação, comprometimento com o aprendizado, curiosidade para aprender, conexão com a realidade. As opiniões coincidem com Wood (2003, p. 84): “A capacidade de se manter numa tarefa e ignorar distrações é, de fato, um sintoma da estrutura do intelecto da criança, e mudanças no tempo de concentração relacionam-se ao desenvolvimento intelectual." No entender de P14, a criança que apresenta atenção é que está conectada à realidade, participando, questionando, buscando solução para os desafios. Toda criança muito quieta não é questão de atenção, muitas vezes, o inquieto apresenta mais dinamismo.

Os sujeitos responderam que o estudante atento é aquele que, mesmo com alguns lapsos de desatenção, quando abordado, retorna às atividades em sintonia com o que está ocorrendo em sala de aula. P1 expressa: Um estudante atento é aquele que, mesmo havendo um determinado momento com dispersão rápida, consegue ter a consciência da importância da atividade que está realizando e volta a concentrar-se novamente. No entender de Fernández (2012, p. 16), isto significa estar “[...]suficientemente distraído para deixar-se surpreender e suficientemente atento para não perder a oportunidade".

P3 considera atento aquele aluno que quando chamado a ler, sabe continuar, e sabe posicionar-se em face de questões abordadas. Faz referências espontaneamente, estabelece relação com o que está sendo constatado. Percebemos que a atenção não necessariamente está relacionada a "ficar quieto". A criança que silencia, muitas vezes está distante do que está acontecendo. A atenção supõe envolvimento, participação, ação e retorno ao que está sendo proposto. "Distração não é o mesmo que desatenção. $O$ movimento entre a distração e a desatenção é o que nos permite aprender." (FERNANDEZ, 2012, p. 39).

Mas como em todos os aspectos nem todos os sujeitos são iguais, não é possível construir um protótipo de estudante atento, pois como é citado por P7, Não há como descrever com extrema exatidão, pois cada sujeito possui suas características próprias. $O$ estudante pode estar nos olhando fixamente, mas talvez sua atenção não esteja voltada para você (professor). Sendo assim, tanto a criança quieta e observadora, quanto a agitada e questionadora, pode ser considerada um estudante atento.

RIAEE - Revista Ibero-Americana de Estudos em Educação, Araraquara, v. esp, n. 3, p. 2026-2040, dez., 2018. E-ISSN: 1982-5587. 
Segundo os professores, o estudante desatento também possui características que podem ser identificadas, como desorganização do material, falta de interesse nas atividades realizadas em sala de aula, agitação, apatia com outros colegas, entre outros, como é destacado por P1: Consigo perceber por meio da apatia, da falta de atenção e interesse pelas atividades, a falta de continuidade nas tarefas, quando é preciso chamar a atenção muitas vezes durante a aula, não se envolve.

Também é apontado por P15 aquele aluno que não se manifesta, que é ausente, não se envolve, mostra-se desmotivado e irresponsável. Também foram destacadas as dificuldades de os estudantes prestarem atenção por estarem inseridos em um mundo com acesso a milhares de informações, onde tudo acontece muito rápido, e o sistema de aprendizagem nem sempre é compatível: Vivemos em um mundo interativo com acesso a milhares de informações, diante deste cenário cada vez mais as crianças têm dificuldades em sentar em sala de aula e manter-se focadas (P13).

Em período recente, pode ser observado ainda um grande aumento nos diagnósticos de $\mathrm{TDAH}^{7}$, quando comparados com algum tempo atrás, o que pode não ser propriamente o aumento da doença, mas sim, maiores dificuldades de atenção, confundidas em diagnósticos equivocados de TDAH, como esclarece Fernández (2012, p. 93): "Existem poucos estudos específicos sobre a capacidade atencional [...]. Realizam-se diagnósticos de déficit de atenção sobre suposições que desconhecem avanços produzidos no século XX com relação ao estudo da subjetividade humana e inteligência".

Os professores e a escola devem levar em consideração e ter presente os avanços e pesquisas na área médica e da ciência cognitiva que contribuem para diagnósticos mais precisos e formas mais efetivas como alternativas a crianças que manifestem tais comportamentos. Não podemos desconhecer que isso pode contribuir muito com o trabalho da escola e com o processo de aprendizagem da criança.

\section{Fatores que determinam a desatenção em sala de aula}

Pedimos aos professores que relatassem possíveis fatores que consideram responsáveis pela falta de atenção em sala de aula. A de maior incidência está relacionada a conversas paralelas e interesse por outras questões ou assuntos. O que faz um estudante

\footnotetext{
${ }^{7}$ Transtorno do Déficit de Atenção com Hiperatividade.
} 
deixar de lado o que está sendo tratado, para interessar-se por outro assunto? Alguns professores falam em imaturidade, problemas familiares, fatores externos, falta de comprometimento, mas algumas respostas remetem a questões de problemas psicológicos, emocionais e peculiaridades, como transtornos de déficit de atenção e hiperatividade.

P4 diz que A causa está na falta de interesse e acompanhamento familiar. Estudantes sem perspectiva de vida. Currículo fora de contexto e realidade dos estudantes. A relação entre os pais e a criança tem uma extrema importância no desenvolvimento da aprendizagem. Respaldam nosso entendimento autores como Rodrigues, Sobrinho e Silva (2000, p. 40), os quais atribuem à família a capacidade de desenvolver a consciência crítica, mas também o sentimento de responsabilidade de limites. P2 responsabiliza também o professor ao afirmar que os estudantes se dispersam e não demonstram interesse em função da metodologia empregada pelo professor. A ansiedade por brincar, pelo recreio, também foi lembrada.

P1 identifica nas crianças ansiedade gerada por adultos que não possuem tempo, ou paciência para conversar com eles a respeito de seu estudo. As crianças não nascem naturalmente com o interesse, ou tendência para o estudo, para ler e escrever, esses elementos são da cultura, adquiridos. Portanto, é preciso fazer um trabalho, dialogar com elas, para que entendam a importância do conhecimento, da escolarização para suas vidas. No entender de Gómez (2015), os aprendizes precisam compreender que a quantidade informação exige seleção, foco e concentração, se não quiserem naufragar em uma tempestade contínua de ruído informacional e disperso. Esta não é uma tarefa somente da escola, a família precisa assumir conjuntamente essa função. Para que haja aprendizado efetivo, a criança precisa estudar em casa, retomar o que foi visto na escola, e são os pais os responsáveis para que isso ocorra. Estudar é um hábito desenvolvido e cultivado. Espontaneamente, raramente irá ocorrer.

P9 destaca que a falta de atenção está relacionada com cansaço, sono, problemas familiares, alimentação e excesso de atividades características: A criança está sobrecarregada, chega na escola em seu limite. Há muitas crianças que são submetidas a uma rotina estressante com excesso de atividades paralelas a escola, não tendo tempo para aquelas atividades da sua idade, são verdadeiros executivos. Essas exigências podem levar as crianças ao esgotamento. O que estamos fazendo com nossos filhos? A infância é uma fase única. Se não viverem esse tempo de forma equilibrada, quais serão as consequências? Para Wood (2003, p. 84) “[...] muitos fatores influenciam o poder de 
concentração das crianças e, assim, exercem uma influência marcante sobre quanto elas aprendem e a rapidez com que o fazem".

P2 diz que, muitas vezes, a desatenção ocorre por pensamentos a respeito de fatores não relacionados à aula (família, amigos, brincadeiras, ensaios, dúvidas...); necessidades oriundas de fatores psicológicos; desinteresse do estudante a partir da metodologia empregada pelo professor. Para P1, esses fatores podem estar relacionados a conteúdos não significativos; imaturidade; ausência de afeto; fatores fisiológicos; ansiedade gerada por adultos; falta de tempo ou paciência dos pais para falar ou interagir com as crianças. As brincadeiras com os colegas, conversas, são citadas por P5. De acordo com Tacca (2008), é grande a responsabilidade dos profissionais da educação na organização dos processos educativos, por serem importantes promotores de processos geradores de unificação e articulação teórico-prática.

P13 afirma que [...]é preciso trabalhar muito de forma lúdica e com materiais diversificados para que a criança adquira o gosto pela leitura e escrita e desta maneira possa evoluir no processo de aprendizagem. Neste sentido, Tacca (2008) afirma que no ensino escolar ainda predomina uma visão de aprendizagem como a reprodução daquilo que se apresenta ao aluno: a aprendizagem é reprodução e não criação.

\section{As tecnologias e a desatenção em sala de aula}

A sociedade humana modernizou-se, evoluiu tecnologicamente, criou novos dispositivos de comunicação, de transmissão de informações, em síntese, aumentou o ruído e obrigou o ser humano a pensar sobre a atenção. Podemos salientar que as Tecnologias Digitais da Informação e da Comunicação (TDIC) são a materialização destes novos tempos em que se comunica com mais facilidade e que os sujeitos têm sido convidados a olhar sob outra ótica para a tecnologia digital.

Sabe-se que hoje o uso de tecnologias é algo indispensável em grande parte das atividades realizadas, tanto para estudantes, quanto fora da escola. Os professores foram questionados sobre a existência da relação entre a atenção em sala de aula e o uso de tecnologias por parte dos estudantes: 16,6\% responderam que não, que ela não existe, e 83,3\% deles responderam que sim. Para P4, alguns aparelhos dispersam ainda mais os estudantes, mas outros servem de estímulo para outro foco ou conteúdo. Já P15 diz que o uso de tecnologias foi limitado na escola em que trabalha, e que esse recurso só é 
permitido em casa. P2 acredita que [...] mesmo utilizando recursos variados, dinâmicas $e$ atividades diferentes, a atenção para a tecnologia, como o telefone celular, prende a atenção de forma muito mais forte e os estudantes acabam se distraindo.

Para Gómez (2015), este novo cenário social também exige mudanças substanciais na formação de futuros cidadãos e, portanto, apresenta desafios inevitáveis para os sistemas educacionais, as escolas, o currículo, os processos de ensino e aprendizagem. $\mathrm{O}$ professor como agente mediador no processo de formação de um cidadão apto para atuar nessa sociedade de constantes inovações, tem como desafio incorporar as ferramentas tecnológicas no processo de ensino e aprendizagem, buscando formação continuada, bem como mecanismos de troca e parcerias quanto à utilização destas. Ou seja, não é possível pensar em estratégias didáticas que não contemplem as tecnologias. Os próprios entrevistados reconhecem esta necessidade, como declara P8: [...] as crianças são muito visuais, celulares, TV, filmes... e a escola precisa se adequar a essa nova realidade.

\section{Considerações finais}

A pesquisa teve como objetivo identificar e interpretar os fatores interferentes nos processos atencionais em estudantes dos anos iniciais do Ensino Fundamental e seu impacto na aprendizagem, na percepção de seus professores. A partir de questionários e diferentes teóricos podemos concluir que a aprendizagem é considerada pelos professores um pré-requisito, somente ocorrendo quando as informações passam pelo filtro da atenção. Com relação às causas da desatenção figuram problemas familiares, o uso indiscriminado das tecnologias e a metodologia utilizada pelo professor, ponto que suscitou, junto aos entrevistados e à bibliografia consultada, a importância do papel da família, bem como das práticas pedagógicas acompanharem o mundo contemporâneo.

$\mathrm{O}$ estudante atento foi caracterizado como aquele que, mesmo distraindo-se em alguns momentos, tem a consciência da importância de voltar a concentrar-se, participa em aula e responde às atividades requeridas. Já o estudante desatento seria mais desorganizado com seu material e mais calado. Também foram apontados alguns casos de TDAH, que acabam dificultando o aprendizado. Neste sentido, permanece o alerta de diversos autores sobre a verdadeira necessidade de medicação e sobre a importância da formação de professores numa perspectiva contemporânea para abordar o tema.

RIAEE - Revista Ibero-Americana de Estudos em Educação, Araraquara, v. esp, n. 3, p. 2026-2040, dez., 2018. E-ISSN: 1982-5587. 
Com relação à tecnologia e desatenção, os entrevistados encontram como verdadeira esta relação, mas também admitem que atividades dinâmicas alcançam uma melhora na atenção por parte dos estudantes, e que devem ser utilizadas com frequência contanto que relacionem e auxiliem no aprendizado. O professor precisa manter o olhar sensível e vigilante em sua prática e a forma como organiza e conduz a aula para que sempre que necessário reconstrua seu planejamento e repense suas estratégias no sentido de atender às características dos aprendizes da classe que atende.

Modestamente, esta pesquisa buscou trazer subsídios à formação e à prática docente, que enfrenta o desafio de adaptar-se à contemporaneidade, buscando suscitar novos estudos e investigações. Neste sentido, foi à sala de aula buscar seus insumos e relacioná-los com a bibliografia consultada, posto que acreditamos que a formação se faz nesta dinâmica da teoria examinada à luz da prática. Outros questionamentos ficam por serem feitos, como: que estratégias didáticas são utilizadas pelos professores para contemplarem a atenção dos seus estudantes? Os artefatos tecnológicos poderiam ajudar a diminuir as dificuldades de aprendizagem? Como? Seria interessante um resgate mais profundo da epistemologia da aprendizagem, de modo a melhor entender como ela se dá na contemporaneidade? Está aberto o debate.

\section{REFERÊNCIAS}

BARDIN, Laurence. Análise de conteúdo. São Paulo: Edições 70, 2008.

BRANDÃO, Marcus Lira. As bases biológicas do comportamento: introdução à neurociência. São Paulo: Pedagógica e Universitária, 2004.

CASTELLS, Manuel. A sociedade em rede I: a era da informação: economia, sociedade e cultura. São Paulo: Paz e Terra, 2000.

COSENZA, Ramon. A neurociência da atenção. Revista Neuroeducação, São Paulo, quinta edição, p. 25-31, 2015.

De-NARDIN, Maria Helena; SORDI, Regina. O. Aprendizagem da atenção: uma abertura à invenção. Revista Iberoamericana de Educación, n. 47/4, p. 53-61, 2008.

DUTRA, Luiz Henrique de A. Epistemologia da Aprendizagem. Rio de Janeiro: DP\&A editora, 2000,

FERNANDEZ, Alícia. A atenção aprisionada. Porto Alegre: Artmed, 2012. 
FFIELD, M. Aprendizagem ativa na educação infantil. In: VICKERY, A. Aprendizagem ativa nos anos iniciais do ensino fundamental. Porto Alegre: Penso, 2016.

GAZZANIGA, Michel [et. al.] Neurociência cognitiva: a biologia da mente. Porto Alegre: Artmed, 2006.

GOLLEMAN, Daniel. Foco: a atenção e seu papel fundamental para o sucesso. Rio de Janeiro: Objetiva, 2014.

GÓMEZ, Ángel I. P. Educação na era digital: a escola educativa. Porto Alegre: Penso, 2015.

IZQUIERDO, Ivan. Questões sobre memória. São Leopoldo: Unisinos, 2004.

IZQUIERDO, Ivan. Memória. Porto Alegre: Artmed, 2002.

KASTRUP, Virgínia. A aprendizagem da atenção na cognição inventiva. Psicologia \& Sociedade, 16 (3), p. 7-16, set/dez., 2004.

PINTO, Amâncio da Costa. Memória, cognição e educação: implicações mútuas. In: DETRY, Brigitte; SIMAS, F. (Orgs.). Educação, cognição e desenvolvimento: textos de psicologia educacional para a formação de professores. Lisboa: Edinova, 2001.

POZO, Juan Ignácio. Aprendizes e mestres. Porto Alegre: Artmed, 2002.

RODRIGUES, Maria Socorro Pereira; SOBRINHO, Elísio Holanda Guedes; SILVA, Raimunda Magalhães. A família e sua importância na formação do cidadão. Família, Saúde e Desenvolvimento, v. 2, n. 2, 2000, p. 40-48.

TACCA, Maria. Aprendizagem e trabalho pedagógico. Campinas/SP: Alínea, 2008.

VICKERY, A. Aprendizagem ativa nos anos iniciais do ensino fundamental. Porto Alegre: Penso, 2016.

WOOD, David. Como as crianças pensam e aprendem. São Paulo: Loyola, 2003.

\section{Como referenciar este artigo}

NOGARO, Arnaldo.; JUNG, Hildegard Susana.; SIMÕES, Estela Mari Santos. O que representa a atenção para a epistemologia da aprendizagem na contemporaneidade? - A percepção docente. Revista Ibero-Americana de Estudos em Educação, Araraquara, v. esp, n. 3, p. 2026-2040, dez., 2018. E-ISSN: 1982-5587. DOI: 10.21723/riaee.unesp.v13.iesp3.dez.2018.10928

Submetido em: 21/01/2018

Revisões requeridas: $16 / 05 / 2018$

Aprovado em: 10/07/2018

RIAEE - Revista Ibero-Americana de Estudos em Educação, Araraquara, v. esp, n. 3, p. 2026-2040, dez., 2018. E-ISSN: $1982-5587$. 